\title{
Dynamic stakeholder interaction analysis: Innovative smart living design cases
}

\author{
Sam Solaimani • Nick Guldemond • Harry Bouwman
}

Received: 6 November 2012 / Accepted: 19 August 2013 / Published online: 29 September 2013

(C) The Author(s) 2013. This article is published with open access at Springerlink.com

\begin{abstract}
In order to become more innovative, companies that operate in the Smart Living domain increasingly initiate and participate in networked business environments that transcend industry boundaries. Inter-organizational collaboration is often characterized by conflicting strategic interests and incoherent operational business processes and procedures. Although many scholars and practitioners use stakeholder analysis to gain insight into the actors' relationships and interactions, existing literature on stakeholder analysis focuses mainly on high-level strategic analysis, often limited to a conceptual and static understanding of stakeholder interests. In this paper, it is argued that a 'true' understanding of stakeholders can be achieved by looking at their interactions and interdependencies at a more detailed level. This study uses a conceptual framework from the service innovation and business model domain, the VIP framework, to extend stakeholder analysis by including an analysis of their dynamic interactions and processes. The qualitative evaluation of the framework's application in illustrative design cases shows that this
\end{abstract}

Responsible Editor: Ulrike E. Lechner

S. Solaimani $(\bowtie) \cdot H$. Bouwman

Faculty Technology, Policy, and Management,

Delft University of Technology, Jaffalaan 5,

2628 BX Delft, The Netherlands

e-mail: h.solaimani@tudelft.nl

H. Bouwman

e-mail: w.a.g.a.bouwman@tudelft.nl

N. Guldemond

Faculty Electrical Engineering, Mathematics \& Computer Science

Department Interactive Intelligence,

Delft University of Technology, Mekelweg 4,

2600 AA Delft, The Netherlands

e-mail: n.a.guldemond@tudelft.nl

H. Bouwman

IAMSR, Åbo Akademi, Turku, Finland extension provides additional insights into stakeholders, and their potential operational conflicts and critical dependencies. By making these conflicts and interdependencies explicit, products and services are potentially easier to implement and commercialize.

Keywords Stakeholder analysis · Business models ·

Networked business $\cdot$ Inter-organizational systems smart living

\section{Introduction}

Over the last three decades, the concept of Smart Homes, which originally focused mainly on home automation, has evolved into broader concepts like Ubiquitous Computing, Ambient Intelligence, Internet of Things and, more recently, Smart Living. Collaborations in the Smart Living domain not only transcend the limited physical boundaries of the living environment, they also cross business and industry boundaries. Firms are increasingly looking for new opportunities within and beyond their existing ecosystems and work together with actors from related industries. With the emergence of product and services innovations across business and industry boundaries, the identification and management of stakeholders has become more complex (Bunn et al. 2002), as has the need to balance the conflicting business model requirements, practices and processes of inter-organizational business partners. A common approach that is used to reduce this complexity is 'stakeholder analysis', the aim of which is to understand a system by identifying its key actors or stakeholders and assessing their respective interest in the system in question (Grimble and Wellard 1997). Although many publications have examined a wide variety of topics related to stakeholder identification and analysis (Donaldson and Preston 1995), strategic management literature is mainly dominated by high-level, mainly static, interpretation of 
stakeholders interests, their interactions and requirements, rather than determining what the implications are for the implementation of innovative systems and the associated business models of networked businesses. Business Model literature has insufficiently examined the operational arrangements of inter-organizational collaboration to exploit innovations and innovative business models (Bouwman et al. 2013). Most stakeholder publications focus on topics like stakeholder analysis definition, classification, application domain and abstract incremental methods to perform the analysis, as perceived by one individual core actor. However, scant attention is paid to changing stakeholder requirements and arrangements, in particular, stakeholders involved in networked businesses. This paper contributes to stakeholder literature as well as to business model literature by analyzing the dynamic interactions and processes between stakeholders in a networked business environment.

In practice, there are developments in two directions. To begin with, stakeholders and their interactions within networked ecosystems are continuously changing, which means that a static approach does not reflect reality and leads to business model designs in which the exchange of value is unbalanced, information-sharing is complex, and operational process are not aligned. As a result, many innovative projects do not materialize. Examples can be found in (e)healthcare, smart living projects that focus on ambient assisted living, eGov projects, etc. (Solaimani et al. 2013). Bouwman et al. (2013) suggest a dynamic approach in which stakeholders, including intended users, are involved in every phase of the design project, from ideation to commercialization, focusing on the artefact and user requirements, as well as on the business model(s) of the networked businesses designing and providing the core service. Secondly, in operational terms, a stakeholder analysis and a business model analysis should always and systematically take stakeholder interactions into account, connecting business models to value exchange, information sharing and business processes alignment. The aim of this paper is to propose a framework that applies existing stakeholder and business model approaches to a networked environment and to carry out an analysis of the operational interactions of stakeholders in three small-scale illustrative design cases. The research question is: how can dynamic, operational interactions between networked stakeholders be made explicit in different phases of a design process? To answer this question, the paper is organized as follows. First, a discussion is provided of existing stakeholder analysis literature. To capture the relevant characteristics of a network-based stakeholder analysis, i.e. the dynamics and operational interactions, the Value, Information and Process (VIP) framework (Solaimani and Bouwman 2012) is introduced. According to this framework, the operational components that need to be taken into account are values and information created by and exchanged between stakeholders as well as operational processes running through and across stakeholders. The framework is applied in three small-scale explorative design cases. Explorative design cases are employed to qualitatively explore whether and how the VIP framework may contribute to understanding stakeholders dynamics from an operational level. The paper concludes with a discussion about the contribution that this study may have for the traditional well-established stakeholder analysis, both from an academic and practical viewpoint.

\section{The concept of stakeholder analysis}

Since the formal introduction of the stakeholder concept in 1963, the concept has appeared in an international memorandum at the Stanford Research Institute (Freeman 1984), and numerous books and articles have been published on this concept (Donaldson and Preston 1995). Freeman defines the concept of stakeholder in relatively broad terms: “.... any group or individual who can affect or is affected by the achievement of the organization's objectives" (Freeman 1984, p. 46). Publications on stakeholders have focused in areas as diverse as strategic management, international relations, policy development, participatory research and ecology to natural resource management (Ramírez 1999). Even more publications have appeared on the subject of stakeholder analysis (Preston and Sapienza 1990), which uses a range of tools to identify and describe stakeholders on the basis of their attributes, interrelationships and interests, in relation to a given issue (Ramírez 1999; Pouloudi and Whitley 1997). Some scholars associate stakeholder analysis with the elicitation and satisfaction of the expectations of stakeholders (Mason and Mitroff 1981; Freeman 1984), while others focus on concepts like fairness, equity and social rights (Gibson 2000) or ethical values (Goodpaster 1991) as concepts that have a major relevance to stakeholders. Simmons and Lovegrove (2005) demonstrate the value of stakeholder analysis with regard to performance management as a 'middle ground' research method. In the area of requirements engineering, Sharp et al. (1999) emphasize the relevance of stakeholder theory as a domain-independent, effective and pragmatic approach to eliciting stakeholder requirements. In addition, a comprehensive understanding of stakeholders and their potential influence on the organization -either positive or negative- is ought to be essential in determining strategic marketing planning and marketing strategy formation (Polonsky 1996; Clulow 2005).

Literature on stakeholder analysis also shows that several authors have attempted to identify and classify stakeholders. Mitchell et al. (1997) focuses on an explicit recognition of situational uniqueness and on management prioritization of 
stakeholder (strategic) relationships, identifying stakeholders on the basis of (1) their power to influence a firm, (2) the legitimacy of their relationships with the firm and (3) the urgency of their claims on the firm. Clarkson (1995) classifies primary stakeholders, i.e. stakeholders who are essential to the survival and well-being of an organization, and secondary stakeholders, i.e. stakeholders with whom an organization interacts, but these interactions are complementary rather than essential. In this paper, we focus on the latter.

Existing literature also provides different models and approaches to designing and carrying out a stakeholder analysis. Mason and Mitroff (1981) propose a four-stage approach: (1) identification, (2) generation of assumption about stakeholder expectations, (3) evaluation of the assumptions and (4) selection of strategies based on the evaluated assumptions, while Elias et al. (2002), Schmeer (1999) and, more recently, Enserink et al. (2010) have also developed staged models for a systematic stakeholder analysis, proposing a six-stage analysis approach consisting of (1) problem formulation, (2) inventory of the stakeholders involved, (3) development of a chart to illustrate the stakeholders' formal tasks, authorities, relations and current legislation, (4) identification of interests, objectives and problems, (5) identification of the interdependencies between stakeholders and, finally, (6) identification of the consequences with regard to the problem formulated initially.

In addition to these staged methods, there are a number of tools aimed at facilitating stakeholder analysis, including Crosby (1992), who provides a stakeholder matrix, Sambamurthy and Desanctis (1990), who use Group Decision Support Systems (GDSS), Gupta (1995), who proposes a conceptual stakeholder map, Varvasovszky and Brugha (2000), who provide a set of preliminary interrelated questions combined with qualitative research methodologies (e.g. interview, Delphi methods) to identify and understand stakeholders needs, relationships and interests, and Bourne and Walker (2005), who provide a mapping tool to visualize the power, influence and contribution of stakeholders within a given organization.

Thus far, existing stakeholder literature has mainly been strategic and problem-solving in nature. However, stakeholder analysis also plays an important role in design research. Several frameworks have been proposed to identify and understand stakeholder requirements, originating from various disciplines, including Information System (IS) design, Software Development and System Design. Chung et al. (1999), for instance, provide a model that systematically represents and addresses the quality requirements during architectural enterprise design, by focusing on stakeholder dependencies. Hummel et al. (2002) argue that the use of methods supporting and managing the knowledge of the stakeholders involved improves stakeholder model design processes, while Bergman et al. (2007) emphasize the relevance of the organizational and political context design, arguing that significant improvements in systems design can be achieved by focusing on questions like (1) what system(s) can be built and delivered within the given environment, and (2) how can stakeholder interests be aligned with the proposed designs to mobilize willingness and resources. Herder et al. (2008) combine a technical and social system design to acquire a better understanding of the behaviour of complex socio-technical systems, and to effectively support better designs and design processes. Pohl (2010) proposes a requirements engineering framework that consists of the core requirements of engineering activities, with the aim of establishing the vision within the existing context, techniques for eliciting, negotiating and documenting as well as validating, and managing the requirements of software-intensive systems.

The actual process of stakeholder requirements elicitation is conducted via the so-called trawling techniques collected and presented by Robertson (2000), including interviewing (Herder and Stikkelman 2004), simulation models (e.g., scenarios, prototyping) (Chung et al. 1999), use-case workshops (Luqi and Kordon 2008). Several methodologies are used to identify and formalize stakeholder requirements, examples of which are Natural Language Processing (NLP), used to analyse the dialogues between stakeholders (Sawyer et al. 2008; Kof 2008), the $i^{*}$ framework (Yu 1997; Chung et al. 1999), used to reveal goals, tasks resources of and exchanges between the stakeholders (Teruel et al. 2011), meta-model, used to reveal the values being exchanged and the design variables, constraints and performance indicators (Herder and Stikkelman 2004). Ballejos and Montagna (2011) propose a model representing the stakeholders and their roles, interest and influence attributes, while the KAOS framework, proposed by Van Lamsweerde (2001), is used to elicit, specify and analyse goals, requirements, scenarios and responsibility assignments.

Most of these techniques and models, however, insufficiently reflect on (1) the operational arrangement of the primary stakeholders involved in inter-organizational innovative design projects, and (2) the dynamic character of their roles, interactions and interdependencies. With regard to the former, many approached focus predominantly on an abstract, more strategic understanding of stakeholder interests and requirements, rather than identifying what operational interaction components are and how they affect innovative applications, products or services. Moreover, the question as to what the best way is to analyse these inter-organizational interaction components is rarely addressed. There are a few approaches that focus on the more operational aspects. In particular when the design of Information Systems is at stake, the focus becomes clearer. In essence, in that case, stakeholders include anyone who operates, benefits from or develops the system, as well as anyone within the inter-organizational ecosystem who has to relate their existing systems to the new system. This paper focuses on cases where multiple organizations have to align their information systems, their value and information exchanges and their operational processes, while at the same time having to keep their 
eye on their business model. Existing models, like the $i^{*}$ framework, merely focus on goals, tasks and resources, while (information) architectural approaches, only include information as a resource. In addition, most existing approaches adopt a static view on the stakeholders involved and their interactions, defining future interactions based on current analysis. Generally speaking, these static approaches are used in the first stage of design, for example during the ideation and requirement elicitation phases of a design cycle. Stakeholder requirement and relationship analysis are not meant to be reiterated throughout the different phases of a design project. For instance, in the case of Agile (software) projects, business requirements are explicated only in the initial ideation phase (Bouwman et al. 2012). Also, in large multi-party $R \& D$ projects where prototypes are developed, the question is raised in the commercialization phase who is going to exploit the artefact that has been developed and how the relevant stakeholders have to align the exchange of value and information and operational processes to exploit the artefact. Consequently, Bouwman et al. (2013) argue that stakeholder analysis should not serve as a commercial validation of the final product, service or artefact, but that the focus should be on stakeholder involvement and requirements in all the phases of an innovation, $\mathrm{R} \& \mathrm{D}$ or design project, from ideation to commercialization,. Stakeholders should be involved in the entire process to capture and evaluate their interests, the dynamic behaviour of stakeholders and their changing requirements, and their mutual interdependencies, while being aware that stakeholder objectives and focus change or are replaced, because there is a need for other resources and assets in different phases of a project. .

With regard to stakeholders, it is also important to emphasize the role of users as a separate stakeholder category. Usually, methods and tools used to develop user-centric designs are elaborated in far greater detail than tools aimed at involving other stakeholder groups in design processes. Contextual interviews, participatory observation, Group Decision Support sessions, individual (open) interviews, conjoint analysis, lab experiments and field trials, are only a few examples. Actively involving users as members of the design team is another example. Generally speaking, user-centric design is well-established and sufficient attention is paid to the identification of user requirements, which is why users are not discussed as stakeholders in great detail in this paper.

To take existing stakeholder analysis models a step further, in the next section, an approach is proposed in which stakeholder analysis is enriched with insights related to more operational inter-organizational stakeholder arrangements.

\section{An extended stakeholder analysis approach}

In this paper, it is argued that a real challenge throughout any design project is aligning the business objectives of stakeholders with the underlying operational arrangements when moving from ideation to commercialization. This alignment requires an in-depth understanding of stakeholders and their multiple, mutual relationships, which can only can be achieved by breaking open the stakeholder interactions. This paper zooms in on stakeholder interactions, which means that the stakeholder analysis is de facto separated from its traditional, more strategic, definition, and the focus shifts towards a framework that is developed and applied in the area of service innovation, design and engineering (Solaimani and Bouwman 2012). The framework analyses the interdependencies and dynamic operational arrangements between the primary stakeholders in three domains: (1) the 'value domain', which describes which value objectives are defined, which value objects (resources and capabilities) are needed, what value activities are executed and how value creation is interdependent; (2) the 'information domain', which describes which information needs to be available and how information is created and exchanged between stakeholders and what interdependencies exist, and (3) the 'primary business processes', providing a detailed description of the primary business activities shared and performed by the stakeholders (see Fig. 1).

Each domain contains multiple sub-components. The value objects and activities describe the value-creating actors (i.e. the stakeholders and end-users), the dynamic relationship between the actors, the value they create, exchange and
Fig. 1 The VIP framework (adapted from Solaimani and Bouwman 2012)

\begin{tabular}{|c|c|c|c|c|}
\hline Value & Stakeholders & $\begin{array}{l}\text { Value Objects, } \\
\text { Value Propositions } \\
\text { (Business Goals) }\end{array}$ & Value Activities & $\begin{array}{l}\text { Value } \\
\text { Dependencies }\end{array}$ \\
\hline Information & $\begin{array}{l}\text { Information } \\
\text { Access } \\
\text { (Authorization) }\end{array}$ & $\begin{array}{l}\text { Information, Data, } \\
\text { \& Knowledge } \\
\text { Objects }\end{array}$ & $\begin{array}{l}\text { Information } \\
\text { Flow }\end{array}$ & $\begin{array}{l}\text { Information } \\
\text { Dependencies }\end{array}$ \\
\hline Process & $\begin{array}{l}\text { Business } \\
\text { Process Units } \\
\text { (Boundaries) }\end{array}$ & $\begin{array}{l}\text { Primary Business } \\
\text { Processes }\end{array}$ & $\begin{array}{l}\text { Business Process } \\
\text { Behavior }\end{array}$ & $\begin{array}{l}\text { Business Processes } \\
\text { Dependencies }\end{array}$ \\
\hline & $\begin{array}{l}\text { Business } \\
\text { Network }\end{array}$ & $\begin{array}{c}\text { Resources \& } \\
\text { Capabilities }\end{array}$ & $\begin{array}{l}\text { Relations \& } \\
\text { Interactions }\end{array}$ & $\begin{array}{l}\text { Interdependencies } \\
\text { \& Responsibilities }\end{array}$ \\
\hline
\end{tabular}


sustain, and their interdependencies. The information-oriented components analyse the actors' access to data, information and knowledge as well as the flow of information and the information dependencies. The business process-oriented components contain the primary business processes, which allow the actual value to be created. In addition, process behaviour and dependencies are subject to analysis in this domain. The Value, Information, Process (VIP) framework (Solaimani and Bouwman 2012) has an integrative and hierarchical structure. Insights gained from the higher value layer can be related to the lower information level, or to the process level. Within the various levels, a distinction between actorrelated components, interaction-related components and emerging dependencies can be described. The interplay between the domains and components involved can be a source of conflict between different actors. The next section contains the description of three small scale design projects in which the model is used to understand the idiosyncrasies of the networked businesses at play in each specific case.

\section{Three illustrative design cases}

The model was used in three innovative design projects carried out by university-based teams. The projects were proposed by a number of companies from various industries. The teams were supported by two coaches from the university and one or two coaches from the companies involved. Each team consisted of five students from different university departments, including industrial design, business and management and computer engineering. The three projects were related to healthcare, mobility and energy, all relevant topics from a Smart Living perspective. The Mobility project examined the possibilities to support car drivers by an automatic, or 'smart', merging on highways. The team analysed various scenarios with regard to an ICT-supporting system to be used inside cars. Simulation tools were used in the implementation phase to assess and evaluate the proposed scenarios. The aim of the Energy project was to help a municipality in the Netherlands to become fossil-free by 2020 . The goal was to develop a system that provides a real-time calculation and visualization of the financial impact of the green investments of the municipality and energy providers. The system was intended to be accessible via the Internet for all the stakeholders involved. The aim of the Health project was to develop a preventive health system application based on several gaming elements, designed to motivate and facilitate users to adopt a healthier life-style and at the same time improve communication between users and healthcare professionals (including life-style coaches), with the ultimate goal of improving the life-style of patients with diabetes and obesity.

The projects were intended to run for a period of 6 months, divided into four phases, reflecting the phases in a design process (ideation, conceptualization, implementation and commercialization). In the first two phases of the projects, the traditional strategic stakeholder analyses were carried out: identification of the stakeholders, business requirements and priorities (as suggested by Freeman 1984; Mason and Mitroff 1981). In line with Mason and Mitroff (1981), Crosby (1992), and Enserink et al. (2010), the teams were requested to 1) define the problem, 2) identify the stakeholders, stakeholder interests and resources involved, 3) generate assumptions regarding stakeholder expectations (and requirements), and 4) evaluate the position of the various stakeholders (either in favour or against) with regard to project objectives. Table 1 presents a detailed picture of how the teams involved the stakeholders, where their focus lay and what the outcome was of their approach, throughout the different project phases. The teams used various sources (including several open and semi-structural interviews) to obtain detailed insight into the stakeholders involved, including the users, and their needs and limitations. In general, the teams posed various 'how' and 'what' questions, not only to gain an in-depth understanding of the explicit business requirements of the stakeholders, but also to understand the less visible operational challenges. Additionally, during the first phase, the teams and the industry and university partners carried out a preliminary literature review and a market analysis, including relevant legislation and regulation, local or national government policies, technology and business reports, Internet resources and stakeholder websites. They also conducted (open) interviews with stakeholders, with the aim of writing an initial business plan, and talked to intended end-users, either face-to-face or via group interviews (see Table 1). In all cases, the focus was on understanding the problem as well as the legal and political boundaries of the design space (especially in Mobility and Energy projects) or the boundaries that existed as a result of relationship between doctors and patients. The business plans included an introduction, a problem statement and an initial stakeholder analysis, a market analysis and business model alternatives.

In the second phase, the teams worked out their business plan and business model, and described how the intended business would create and capture value for users and stakeholders. They discussed their intended business from four different business model perspectives: the service to be delivered, the technological architecture, organizational arrangements and finance (in accordance with Bouwman et al. 2008). Stakeholder and business requirements were essential in this phase of all the projects, with an emphasis on the financial and legal requirements in the Mobility case, (inter-organizational) information system interoperability in the Energy case and the relevance of gaming in Healthcare case. In the healthcare project, storyboard sessions with end-users were organized. Information that was needed to formulate and agree on the business model made it necessary to conduct another round of 
Table 1 Stakeholder management throughout different phases

\begin{tabular}{lc}
\hline Teams & Stakeholders involvement \\
\hline Mobility Ideation & Stakeholders: multiple open \\
& interviews \\
& Users: small scale survey among \\
drivers
\end{tabular}
drivers
Conceptualization Stakeholders: Individual semi- structural interviews the leading companies managers
Users: interview with a number of drivers

Implementation

Stakeholders: brainstorm session with the leading companies technicians and management

Users: simulation tool to evaluate users-requirements

Commercialization Stakeholders: Discussion with the leading stakeholder regarding project follow-up

Users: planning simulation experiment with drivers in future

Energy Ideation

\section{(e.g., farmers), and consumers
Conceptualization}

Stakeholders: Open interview with a wide range of stakeholders varying from governmental institutes, NGO's, energy providers

Users: interview with both prosumers

Conceptualization Stakeholders: Few collective meetings with the nongovernmental companies (enables by the municipality), and semistructural interviews with related companies

Users: semi-structural interviews with prosumers and customers

$\begin{array}{ccc}\text { Implementation } & \begin{array}{c}\text { Stakeholders: Prototyping together } \\ \text { with stakeholders }\end{array} & \begin{array}{c}\circ \text { Data regarding green } \\ \text { investments }\end{array} \\ & \begin{array}{l}\text { Users: semi-structural interviews with } \\ \text { one of the most active users }\end{array} & \circ \text { Technical requirements } \\ & \circ \text { Business and processalignment } \\ \text { Commercialization } & \begin{array}{l}\text { Stakeholders and users: Presentation } \\ \text { of the final solution at municipality }\end{array} & \circ \text { Broad diffusion of software } \\ & \text { with the presence of various public } & \\ & \text { and private companies }\end{array}$

- Project planning,
Teams' focus Outcome
- Understanding the problem statement,

- Identification of projects

limitations (e.g., the problems of cars merging on highways, law and regulation, finance, and user

- Financial planning

- Business requirements, including technical potentials and project uniqueness

- Encouraging the leading partner to provide more resources

- Technical requirements (e.g., requirements elicitation and morphological analysis)

- Simulation criteria (e.g., security, comfort)

- System operation evaluation (e.g., technical feasibility)

- Business and process alignment

- Scalability (and finance)

- Understanding the problem statement,

- Law and regulations

- Local policies

- Companies business

- Reaching a consensus on business objectives

- Stakeholders' systems interoperability, perceptions) requirements
- An initial business plan and business model
- Preliminary stakeholder analysis (mainly focused on the identification of actors and their interests and resources)

- Stakeholder analysis

(business objectives)

- Developing a (collective) business model

- Being invited to work on the project inside the company with an intensified collaboration as a consequence

- Evaluation of the solution using an advanced computer simulation tool

- The leading company has set up a new follow-up project (e.g., experimenting with actual drivers)

- An early business plan and business model

- Stakeholder identification (due to large number of actors)

- A long list of business requirements of the involved stakeholders

- A (collective) business model for a public use, with information regarding green investment of the participating companies

- The list of requirements were to conflicting and complex that the team chose to exclude individual consumers

- Software mock-up, only to be used by municipality and professional users

- In the end, the software was not adopted by the companies, for strategic reasons, and the software was not launched online. However, the municipality did adopt the software, to calculate the impact of green investments on overall performance, as the information required is already in possession of municipality. Nevertheless, the municipality is urged to use the software and companies data confidentially. 
Table 1 (continued)

\begin{tabular}{|c|c|c|c|c|}
\hline Teams & & Stakeholders involvement & Teams' focus & Outcome \\
\hline \multirow[t]{4}{*}{ Health } & Ideation & $\begin{array}{l}\text { Stakeholders: Focus group with } \\
\text { life-style care providers } \\
\text { Users: interview with small number } \\
\text { of patients }\end{array}$ & $\begin{array}{l}\text { Understanding the problem } \\
\text { statement from medical and } \\
\text { users viewpoint }\end{array}$ & $\begin{array}{l}\text { - An early business plan and business } \\
\text { model } \\
\text { - Stakeholder analysis (identification } \\
\text { and collection of their interests and } \\
\text { expectations), a collection of life- } \\
\text { style improving interventions based } \\
\text { on gaming elements }\end{array}$ \\
\hline & Conceptualization & $\begin{array}{l}\text { Stakeholders: Semi-structural } \\
\text { interview with various healthcare } \\
\text { service providers } \\
\text { Users: interviews with patients and } \\
\text { healthcare providers to make } \\
\text { storyboards }\end{array}$ & $\begin{array}{l}\text { - Financial planning } \\
\text { - Healthcare laws and regulations } \\
\text { (e.g., insurance policies, } \\
\text { medical privacy laws) } \\
\text { - Relevance of several gaming } \\
\text { elements }\end{array}$ & $\begin{array}{l}\text { A business model for the leading } \\
\text { online healthcare provider to include } \\
\text { various gaming elements in } \\
\text { combination with real-life health } \\
\text { coaches }\end{array}$ \\
\hline & Implementation & $\begin{array}{l}\text { Stakeholders: semi-structural } \\
\text { interviews with the leading } \\
\text { healthcare service provider } \\
\text { Users: Testing sessions with patients }\end{array}$ & $\begin{array}{l}\text { - Technical requirements } \\
\text { - Software testing } \\
\circ \text { Business and process } \\
\text { alignment }\end{array}$ & - An online pilot platform(dummy) \\
\hline & Commercialization & $\begin{array}{l}\text { Stakeholders : Semi-structural } \\
\text { interview with the leading online } \\
\text { healthcare provider regarding } \\
\text { solution integration within the } \\
\text { provider's existing platform } \\
\text { Users: pilot with a small number of } \\
\text { actual patients }\end{array}$ & $\begin{array}{l}\text { - Solution replicate-ability } \\
\text { for other diseases }\end{array}$ & $\begin{array}{l}\text { The leading healthcare provider has } \\
\text { integrated the end-solution into its } \\
\text { business. Also, a number of team } \\
\text { members continued their } \\
\text { collaboration after the project ended. }\end{array}$ \\
\hline
\end{tabular}

interviews with stakeholders, especially from the leading company.

Throughout the third phase, the project teams focused primarily on implementing their business plan and on translating the business objectives into a technical plan. Through iterative interviews, the teams attempted to identify the technical requirements, while involving the stakeholders in the technical (functional) design process. In close collaboration with the stakeholders, especially the leading partner, the teams tested or evaluated their ideas in pilot studies, simulation and interviews. Also, the alignment between the previously defined business model and the established infrastructure, systems and processes of the stakeholders, was a subject of analysis.

The teams extended their analysis by focusing on the operational processes that stakeholders have or need to have to realize their business needs. To this end, the teams used the VIP framework (Fig. 1) to analyse the stakeholders' operational arrangements, by focusing on (1) the creation, offering and capture of value between the various stakeholders, including end-users, (2) the creation and exchange of information and information dependencies, and (3) the primary business processes between the various stakeholders. The teams visualised their findings. The analysis was supported by joint drawing sessions in which stakeholders were involved. The drawing sessions and analysis helped the teams to reveal and anticipate operational conflicts, complexities and/or problematic dependencies between the various stakeholders. For instance, the healthcare design case shows the central role of the core service provider in the entire diagram (Fig. 2) and the key role of funding, while at the same time demonstrating that the development of hardware and software plays a minor role in the value creation processes. In addition, the relevant information flows were visualized.

In the Energy project, the visualization of the complex network of information/data exchange between the various actors shows the position of the actors involved with regard to two dimensions, i.e. sustainability and long-term versus shortterm strategic orientation (Fig. 3).

These two dimensions were used to identify who the real primary stakeholders in this project were, and to identify the information flows for the final investment calculation system. Process diagrams related to the actual execution of processes for the Mobility design cases show the essential operational interactions between stakeholders involved (Fig. 4). This high-level process model was later worked out in a more detailed diagram that describes which processes are essential and how processes are interrelated and in what sequence, in order to run the smart merging scenarios (comparable to Business Process Modeling Notion [BPMN] representation with events, activities, lanes and artefacts). ${ }^{1}$

\footnotetext{
${ }^{1}$ For the sake of brevity, only these three illustrative diagrams are reported in the paper. However, additional information, including a detailed process diagram, is available on request.
} 
Fig. 2 Inter-organizational value creation and exchange in Health case

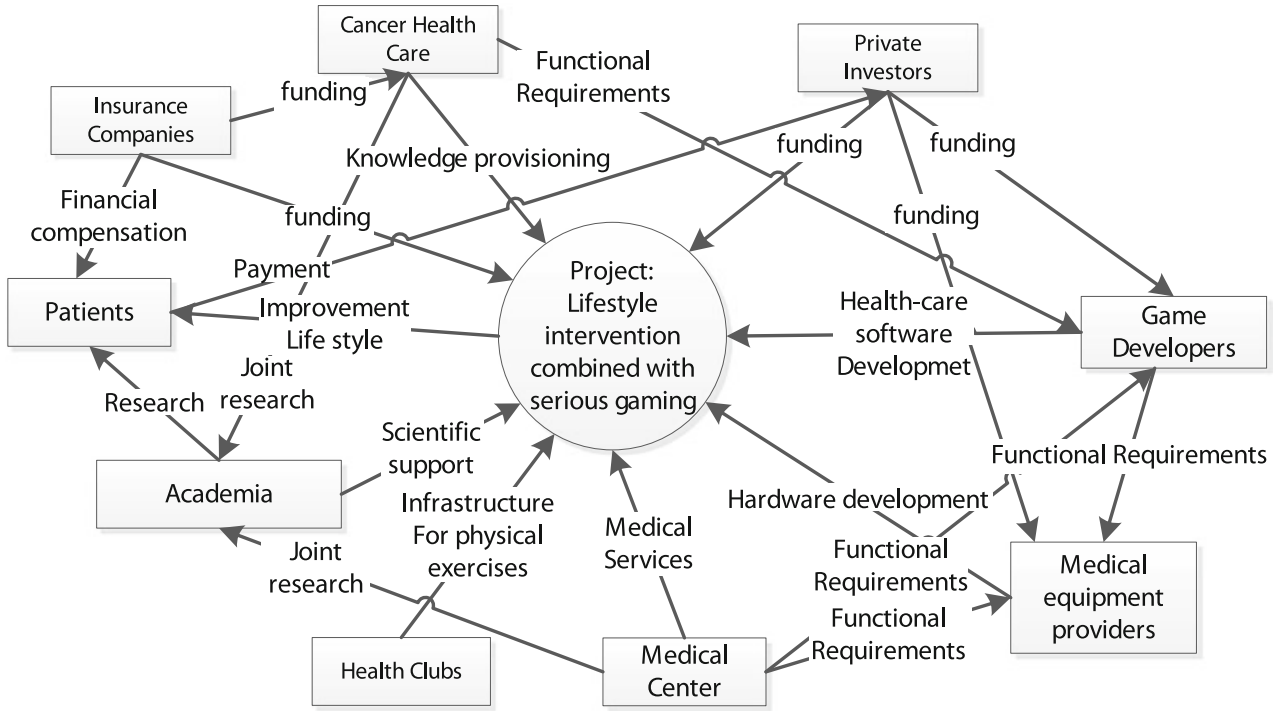

During the commercialization phase, the teams worked towards the delivery of the solutions they had developed. In two cases (Energy and Health), the teams closed the project successfully with a working solution, which was adopted by one of the leading companies. In one case (Energy), the intended solution was only implemented by the leading company and not, as was originally planned, by all the stakeholders. The software is available under the core providers brand.
Fig. 3 Inter-organizational information creation and exchange in Energy case

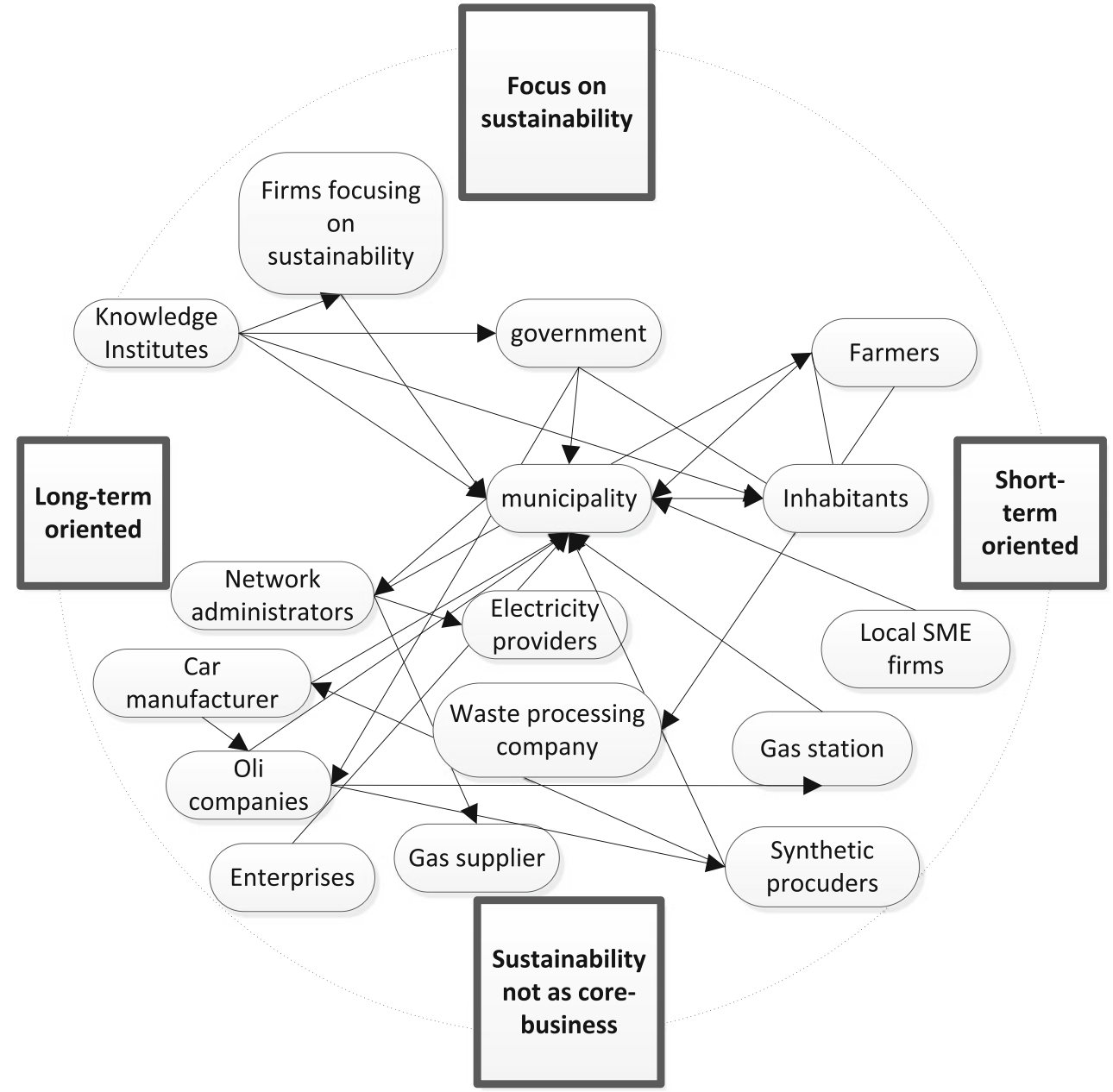


Fig. 4 The inter-organizational business processes in Mobility design case

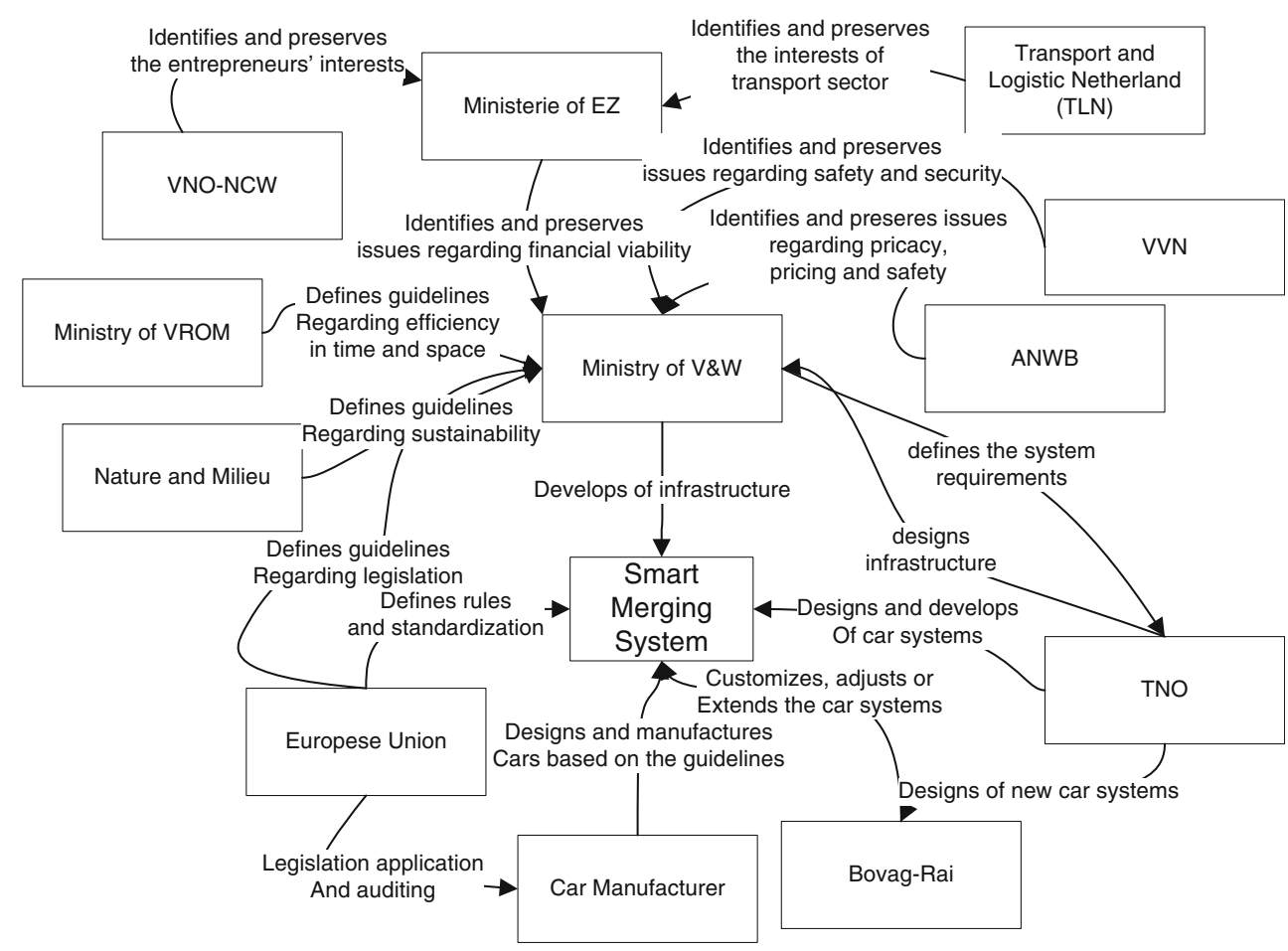

\section{Validation of the use of the extended stakeholder model}

The design projects illustrate the relevance of making both the strategic and the operational stakeholder relationships explicit. The VIP model makes it possible to reveal conflicting interests and conflicting operational processes. Moreover, simple design projects quickly become complex and the VIP diagrams help to illustrate this complexity as well as the co-dependency between the actors involved. To assess the value of the extended stakeholder model and of the VIP diagrams, different project members were interviewed using a semi-structured interview approach. In these interviews, the teams were asked about their understanding of stakeholders before and after using the extended stakeholder framework, and whether the framework helped them anticipate conflicts between stakeholders and formulate a well-defined business implementation plan. In addition, during team meetings, teams were observed to determine 'how teams apply the framework' and 'how they make decisions around stakeholder analysis'. Two sets of responses were collected with regard to (1) the value of the extended stakeholder analysis approach and (2) problems signalled when the approach was used to draw the VIP diagrams in joint sessions. By using the extended frameworks and VIP-diagrams, the teams were forced to consider stakeholder interactions and relationships, information resource dependencies and primary business processes in greater detail: "the analysis gave us a broad and factual view of stakeholders interactions, which sometimes was in contrast with our intuitive image of reality...", according to one participant in the Mobility project, while a participant in the Energy team made a similar remark regarding the level of detail of the insights that had been generated. It also helped the teams to identify the core actors and their relationships with the other stakeholders: "The analysis gave us the chance to think how the business processes of different stakeholders could be connected to each other... and how operational processes were intertwined with the information flow", according to one participant in energy project.

Similarly, the interviews indicate that the experiences of the teams with the model and diagrams were generally positive. "Although...the model was applied to explore the network of stakeholders, we also reconsidered the model to evaluate the services. We needed the analysis to reveal the patient groups and related organizations, and their relations and interactions." It is interesting to note that some of the extended models domains seem to be more useful than others. For example, the Energy project benefited more from the identification of value and information exchange, while the detailed analysis of the stakeholders' business processes turned out to be less relevant. Nevertheless, the combination of all three domains made it possible to arrive at a comprehensive view of the value and information being exchanged between primary stakeholders and their operational interactions. Furthermore, the perceptions of the teams regarding the sequence, connectedness and complementariness of VIP domains and their components were positive. 
The practical usability of the extended stakeholder approach is not always straightforward. One team complained about the abstraction levels of some concepts and definitions, for instance when discussing value exchange. Throughout the analysis, the concept of value is interpreted in different ways. The team discovered that some stakeholders associate value with tangible values, while other stakeholders emphasize intangible benefits. Accordingly, the team adapted their model to cover both types of values. Furthermore, the level of detail with which the VIP concepts had to be described was not always clear. Another issue was the perceived relevance and usefulness of the extended stakeholder model, which seems to vary in different projects and project phases. In the case of the Energy project, for example, the merits of the framework in the implementation phase were not clearly perceived, while in the Healthcare project, the framework was applied during the analysis in both design phases (ideation and implementation). The modelling technique used to visualize the analysis is yet another issue. Although the teams applied their own intuitive approach to visualize the analysis, having access to homogeneous visualization tools seems to be desirable.

\section{Discussion and conclusions}

In the current economy, innovative services and products can only be delivered by organizations that collaborate in creating and capturing value. The collaboration, however, involves and is enabled by activities, processes and information systems at various levels of operations. Stakeholder analysis is emphasized as a promising approach to identify stakeholders and to understand their needs. Literature on stakeholder analysis, however, is relatively abstract, making it difficult to arrive at a practical understanding of how stakeholders and their business/strategic intensions are often constraint by (interorganiztonal) operations. As a result, in many design projects the role of the primary stakeholders (i.e., the collaborating companies at the core of the project) is only analyzed at a strategic level. In this paper, it is argued that, in addition to the analysis of stakeholder policies and strategies, attention has to be paid to stakeholders operations. To analyze stakeholders operations, this paper borrows the VIP framework from business model literature and incorporates the framework in a stakeholder analysis. The proposed model focuses on the exchange of value and information, as well as on operational processes, which is not common in stakeholder literature. In addition, the model enables the analysis of the stakeholder at various operational levels throughout different phases of the design process. By focusing on the link between stakeholders' business intentions and the underlying inter-organizational processes, systems and infrastructure, the paper aims to describe and analyze the dynamic operational interactions, relations and interdependencies in greater detail. The paper empirically explores the concept of extended analysis of stakeholders (i.e. including stakeholders operations) through multiple design cases.

The findings of the analysis shows that the extension was valuable in all three design cases, both interms of (1) helping the design teams to be more detailed about the core operational elements that impede stakeholders (collective) operations, as well as (2) increasing team understanding about - and enabling the identification of - the core value, information and process level operations that stakeholders need to achieve their (collective) business objectives. As such, the framework allowed the teams to develop a comprehensive view of the stakeholders involved and to explicate the interactions, relationships, interdependencies and essential business processes in a more detailed manner. The framework helped explicate how conflicting strategic interests of stakeholders has impact on their relationship at an operational level (e.g., conflicting systems integration and information access). The model made it possible to analyze value and information exchange in concert with operational processes, and to make clear where misalignment between business and operations exist. Hence, this paper argues that the model can serve as an intermediate step in bridging the gap between high-level strategies and business models, on the one hand, and the information systems, workflows and IT-supported processes, on the other. Having said that, this was an explorative design project and further development and validation of the model is needed.

With regard to the further development of the proposed VIP approach, several observed shortcomings can be taken into account, including detailed and context-based operationalisation of the framework's components, development of formal methods to apply the framework, and tools to visualize the outcome. In addition, in terms of validation, there are a number of limitations. First of all, this study was based on a limited number of design cases, and the design projects were not formally developed as a research project. The cases were only used for illustrative purposes and to gain insight into the viability of the framework. Increasing the number of cases would not only improve the validity of the results, but also provide greater insight into the framework's applicability and usefulness in other contexts. In short, this paper should be seen as a first, modest and illustrative attempt to expand stakeholder theories, with the aim of drawing attention to a systematic analysis of the dynamic operational interactions and dependencies among stakeholders, which in turn, helps to anticipate conflicting interactions and to reveal critical interdependencies. Some suggestions for future research are (1) an elaboration on stakeholder analysis operationalization, by means of an extended model, (2) an empirical evaluation of stakeholder analysis operationalization and its impact in a larger open case study setting, and (3) the development of a 
modelling technique designed to integrate and visualize the extended stakeholder analysis.

Open Access This article is distributed under the terms of the Creative Commons Attribution License which permits any use, distribution, and reproduction in any medium, provided the original author(s) and the source are credited.

\section{References}

Ballejos, L. C., \& Montagna, J. M. (2011). Modeling stakeholders for information systems design process. Requirements Engineering, Springer.

Bergman, M., Lyytinen, K., \& Mark, G. (2007). Boundary objects in design: an ecological view of design artifacts. JAIS Journal of the Association for Information Systems, 8(11), 546-568.

Bourne, L., \& Walker, D. H. T. (2005). Visualising and mapping stakeholder influence. Management Decision, 43(5), 649-660.

Bouwman, H., De Vos, H., \& Haaker, T. (2008). Mobile service innovation and business models. Berlin, Heidelberg: Springer-Verlag.

Bouwman, H., De Reuver, M., Solaimani, S., Daas, D., Haaker, T., Janssen, W., et al. (2012). Business models, tooling and research agenda. In R. Clark, A. Pucihar, \& J. Gricar (Eds.), The first 25 years of the bled conference. Kraj: Moderna organizacija. *.

Bouwman, H., de Reuver, M., Hampe, F., Carlsson, C., Walden, P. (2013). Mobile R\&D prototypes; what is hampering market implementation? International Journal of Innovation and Technology Management, 10 (forthcoming).

Bunn, M., Savage, G. T., \& Holloway, B. B. (2002). Stakeholder analysis for multi-sector innovations. Journal of Business \& Industrial Marketing, 17(2/3), 181-203.

Chung, L., Gross, D., Yu, E. (1999). Architectural design to meet stakeholder requirements. In: P. Donohue (Ed.), Software architecture (pp. 545-564). Kluwer Academic.

Clarkson, M. B. E. (1995). A stakeholder framework for analyzing and evaluating corporate social performance. Academy of Management Review, 20(1), 92-117.

Clulow, V. (2005). Future dilemmas for marketers: can stakeholder analysis add value? European Journal of Marketing, 39(9/10), 978-997.

Crosby, B. (1992). Stakeholder analysis: A vital tool for strategic managers. Washington: USAID.

Donaldson, T., \& Preston, L. E. (1995). The stakeholder theory of the corporation: concepts, evidence, and implications. The Academy of Management Review, 20(1), 65-91.

Elias, A. A., Cavana, R. Y., \& Jackson, L. S. (2002). Stakeholder analysis for R\&D project management. $R \& D$ Management, 32, 301-310.

Enserink, B., Hermans, L., Kwakkel, J., Thissen, W., Koppenjan, J., \& Bots, P. (2010). Policy analysis of multi-actor systems. The Hague: Lemma.

Freeman, R. E. (1984). Strategic management: A stakeholder approach. Boston: Pitman.

Gibson, K. (2000). The moral basis of stakeholders theory. Journal of Business Ethics, 26, 245-257.

Goodpaster, K. E. (1991). Business ethics and stakeholder analysis. Business Ethics Quarterly, 1(1), 9-12.

Grimble, R., \& Wellard, K. (1997). Stakeholder methodologies in natural resource management: a review of principles, contexts, experience and opportunities. Agricultural Systems, 55(2), 173-193.

Gupta, A. (1995). A stakeholder analysis approach for interorganizational systems. Industrial Management and Data Systems, 95(6), 3-7.
Herder, P. M., \& Stikkelman, R. M. (2004). Methanol-based industrial cluster design: a study of design options and the design process. Industrial and Engineering Chemistry Research, 43, 3879-3885.

Herder, P. M., Bouwmans, I., Dijkema, G. P. J., Stikkelman, R. M., \& Weijnen, M. P. C. (2008). Designing infrastructures using a complex systems perspective. Journal of Design Research, $7(1), 17-34$.

Hummel, M., van Rossum, W., Verkerke, G. J., \& Rakhorst, G. (2002). Product design planning with the analytic hierarchy process in inter-organizational networks. $R \& D$ Management, $32(5), 451-458$.

Kof, L. (2008). On the identification of goals in stakeholders' dialogs. In: B. Peach, \& C. Martell (Eds.), Monterey workshop 2007, LNCS 5320 (pp. 161-181). Springer.

Luqi, \& Kordon, F. (2008). Advance in requirements engineering: Bridging the gap between stakeholders' needs and formal designs. In: B. Peach, \& C. Martell (Eds.), Monterey workshop 2007, LNCS 5320 (pp. 15-24). Springer.

Mason, R. O., \& Mitroff, I. (1981). Challenging strategic planning assumption. New York: Wiley.

Mitchell, R., Agle, B., \& Wood, D. (1997). Towards a theory of stakeholder identification and salience: defining the principle of who and what really counts. Academy of Management Review, 22(4), 853886.

Pohl, K. (2010). Requirements engineering: Fundamentals, principles, and techniques, 1 st ed. Springer.

Polonsky, M. J. (1996). Stakeholder management and the stakeholder matrix: potential strategic marketing tools. Journal of MarketFocused Management, 1(3), 209-229.

Pouloudi, A., \& Whitley, E. A. (1997). Stakeholder identification in inter-organizational systems: gaining insights for drug use management systems. European Journal of Information Systems, 6 , $1-14$.

Preston, L. E., \& Sapienza, H. J. (1990). Stakeholder management and corporate performance. Journal of Behavioral Economics, 19(4), 361-375.

Ramírez, R. (1999). Stakeholder analysis and conflict management. Cultivating peace: conflict and collaboration in natural resource management (pp. 101-126).

Robertson, S. (2000). Requirements trawling: Techniques for discovering system requirements. London: The Atlantic System Guild Ltd.

Sambamurthy, V., \& Desanctis, G. (1990). An experiment evaluation of GDSS effects on group performance during stakeholder analysis (pp. 79-88). System Science, IEEE.

Sawyer, P., Gacitua, R., Stone, A. (2008). Profiling and tracing stakeholder needs. In: B. Peach, \& C. Martell (Eds.), Monterey workshop 2007, LNCS 5320 (pp. 196-213). Springer.

Schmeer, K. (1999). Stakeholder analysis guidelines, policy toolkit for strengthening health sector reform. World Bank.

Sharp, H., Finkelstein, A., Galal, G. (1999). Stakeholder identification in the requirements engineering process, Workshop on Requirements Engineering Process-DEXA'99, Italy (pp. 387-391).

Simmons, J., \& Lovegrove, I. (2005). Bridging the conceptual divide: lessons from stakeholder analysis. Journal of Organizational Change Management, 18(5), 495-513.

Solaimani, S., \& Bouwman, H. (2012). A framework for the alignment of business model and business processes: a generic model for transsector innovation. Business Process Management Journal, 18(4), 655-679.

Solaimani, S., Bouwman, H., \& Secomandi, F. (2013). Critical design issues for the development of Smart Home technologies. Journal of Design Research,11(1), 72-90.

Teruel, M. A., Navarro, E., López-Jaquero, V., Montero, F., González, P. (2011). A comparative of goal-oriented approaches to modeling 
requirements for collaborative systems, 6th International Conference on Evaluation of Novel Software Approaches to Software Engineering, Beijing, China.

Van Lamsweerde, A. (2001). Goal-oriented requirements engineering: A guided tour, Proceedings 5th IEEE International Symposium on RE, Toronto (pp. 249-263).
Varvasovszky, Z., \& Brugha, R. (2000). How to do (or not to do) - a stakeholder analysis. Health Policy and Planning, 15(3), 338-345.

Yu, E. (1997). Towards modelling and reasoning support for early-phase requirements engineering. In: Proceedings of the 3rd IEEE International Symposium of Requirements Engineering (pp. 226-235). IEEE CS Press. 